\title{
Contribución del cooperativismo colombiano al crecimiento económico por habitante en el periodo 2003-2016
}

DOI: https://doi.org/10.21158/01208160.n88.2020.2499

\author{
Miguel Ángel Alarcón-Conde ${ }^{1}$ \\ Universidad de Castilla-La Mancha \\ miguelangel.alarcon@uclm.es \\ Juan Fernando Álvarez ${ }^{2}$ \\ Pontificia Universidad Javeriana \\ alvarez_juan@javeriana.edu.co
}

Fecha de recepción: 10 de abril de 2019

Fecha de aprobación: 13 de abril d 2020

Cómo citar este artículo / To reference this article / Comment citer cet article / Para citar este artigo:

Alarcón-Conde, M. A.; Álvarez, J. F. (2020). Contribución del cooperativismo colombiano al crecimiento económico por habitante en el periodo 2003-2016. Revista Escuela de Administración de Negocios, (88), 165-188. DOI: https://doi.org/10.21158/01208160. n88.2020.2499

\section{Resumen}

En este artículo se exponen las estimaciones sobre el peso absoluto y relativo que tiene el cooperativismo en las principales magnitudes agregadas de la economía colombiana. Con estas estimaciones se hace posible descomponer el producto interno bruto y su crecimiento en Colombia incrustando los factores del cooperativismo oportunos. Lo anterior se ha tratado en dos series de tiempo: por una parte, en la serie temporal 2003-2010, periodo de crecimiento del cooperativismo, y, por otra, en la serie 2010-2016, periodo de desaceleración en las grandes cifras cooperativas que, en buena parte, vienen a ser consecuencia de la liquidación e intervención de entidades cooperativas en el país. Para lograr el objetivo de estimar el peso absoluto y relativo que tiene el cooperativismo, se realiza un cuidadoso levantamiento y un procesamiento de la información contable que las cooperativas colombianas reportan a la Confederación de Cooperativas de Colombia o Confecoop, junto con información similar de la Superintendencia de Economía Solidaria y las distintas superintendencias. El artículo concluye que el cooperativismo se ha fortalecido y ha contribuido al crecimiento del estándar material de vida de los colombianos en el periodo bajo estudio. De forma paralela, su valor añadido bruto sobre el total nacional se reduce más que proporcionalmente con respecto a lo que lo hizo su emisión de transferencias sociales en especie ampliadas, lo que demuestra la orientación funcional al beneficio común y al interés general desde una propuesta del institucionalismo económico contemporáneo.

Palabras clave: cooperativas; cooperativismo; economía solidaria; producto interno bruto; variables financieras; circuito económico agregado.

\footnotetext{
${ }^{1}$ Licenciado en economía por la Universidad Castilla-La Mancha, Experto Universitario en Informática y Aplicaciones de E-commerce (Universidad de Alcalá de Henares), doctor en economía por la Universidad Castilla-La Mancha. ORCID: https://orcid.org/0000-00017195-7350

2 Economista de la Universidad de los Andes (Venezuela), especialista en evaluación social de proyectos de la Universidad de los Andes (Colombia), máster en economía social y dirección de entidades sin ánimo de lucro de la Universidad de Barcelona, doctor en ciencias sociales de la Universidad de Lisboa. ORCID: http://orcid.org/0000-0002-4362-5655
} 


\title{
Contribution of Colombian cooperativism to the economic growth per inhabitant in the period 2003-2016
}

\begin{abstract}
This article presents estimates of the absolute and relative weight of cooperatives in the primary aggregate figures of the Colombian economy. These estimates make it possible to break down the gross domestic product and its growth in Colombia by embedding the appropriate factors of cooperativism. The above has been dealt with in two time series: on the one hand, the 2003-2010 time series, a period of cooperativism growth; and on the other, the 2010-2016 series, a period of deceleration in the large cooperative figures which, to a large extent, are the result of the liquidation and intervention of cooperative entities in the country. In order to achieve the objective of estimating the absolute and relative weight of cooperatives, the accounting information reported by Colombian cooperatives to the Colombian Confederation of Cooperatives (CONFECOOP by its abbreviation in Spanish) was carefully collected and processed, along with similar information from the Superintendency of Solidarity Economy and the various superintendencies. The article concludes that cooperativism has strengthened and contributed to the growth of the material standard of living of Colombians during the period under study. At the same time, its gross value added on top of the national total is reduced more than proportionally with respect to what its issuance of extended social in-kind transfers did, which shows the functional orientation to the common benefit and the general interest from a proposal of contemporary economic institutionalism.
\end{abstract}

Keywords: cooperatives; cooperativism; solidarity economy; gross domestic product; fi-nancial variables; aggregate economic circuit.

\section{Contribuição do cooperativismo colombiano ao crescimento econômico por habitante no período 2003-2016}

\section{Resumo}

Este artigo apresenta as estimativas do peso absoluto e relativo do cooperativismo nas principais magnitudes agregadas da economia colombiana. Com essas estimativas, é possível decompor o produto interno bruto e seu crescimento na Colômbia, incorporando os fatores cooperativos apropriados. $\mathrm{O}$ exposto acima foi tratado em duas séries temporais: por um lado, na série 2003-2010, o período de crescimento do cooperativismo e, por outro lado, na série 2010-2016, um período de desaceleração nas grandes figuras cooperativas que em grande parte, ocorrem como consequência da liquidação e intervenção de entidades cooperativas no país. Para atingir o objetivo de estimar o peso absoluto e relativo do cooperativismo, é realizado um levantamento cuidadoso e processamento das informações contábeis, que as cooperativas colombianas reportam à Confederação de Cooperativas da Colômbia ou Confecoop, juntamente com informações semelhantes da Superintendência da Economia Solidária e as diferentes superintendências.

$\mathrm{O}$ artigo conclui que o cooperativismo foi fortalecido e contribuiu para o crescimento do padrão de vida material dos colombianos no período estudado. Paralelamente, seu valor agregado bruto sobre o total nacional é reduzido mais que proporcionalmente em relação ao que fez sua emissão de transferências sociais expandidas em espécie, o que demonstra a orientação funcional para o benefício comum e o interesse geral de uma proposta da institucionalismo econômico contemporâneo.

Palabras clave: cooperativas; cooperativismo; economía solidaria; producto interno bruto; variables financieras; circuito económico agregado. 


\section{Contribution du coopérativisme colombien à la croissance économique par habitant sur la période 2003-2016}

\section{Résumé}

Cet article présente les estimations en termes absolus et relatifs du coopérativisme dans les principales mesures agrégées de l'économie colombienne. Grâce à ces estimations, il est possible de décomposer le produit intérieur brut et la croissance colombienne en intégrant les facteurs de coopération appropriés. Ces travaux reposent sur deux époques chronologiques: d'une part, la période 2003-2010 correspondant à une période de croissance du coopérativisme et, d’autre part, la période 2010-2016 correspondant à une période de décélération du coopérativisme résultant de la disparition ou de la mise sous tutelle de coopératives nationales. Pour connaitre l'estimation du poids absolu et relatif du coopérativisme dans l'économie du pays, une investigation détaillée et un traitement minutieux des informations comptables ont été effectués sur la base des données envoyées par les coopératives colombiennes à la Confédération des Coopératives de Colombie (Confecoop) et aux informations reçues par les organismes de controle. L'article conclut que le coopérativisme s'est renforcé et qu'il a contribué à l’amélioration du niveau de vie matériel des Colombiens sur la période étudiée. Parallèlement, le niveau de sa valeur ajoutée brute rapporté au total national a été davantage réduit par rapport aux émissions de transferts sociaux, ce qui démontre l'orientation fonctionnelle du coopérativisme vers l'intérêt général.

Mots-clés: coopératives; coopérativisme; économie solidaire; produit intérieur brut; variables financières; circuit économique. 


\section{Introducción}

$\mathrm{D}$ esde la década de los treinta del siglo XX, el cooperativismo ha tenido presencia en distintas áreas de la economía colombiana. Cooperativas de ahorro y crédito, transporte, vivienda, trabajo asociado, salud, seguros o cooperativas agropecuarias, entre otras, conforman un dinámico subsector empresarial con amplia importancia en la provisión de servicios para sus miembros.

Estas empresas operan conforme a una serie de principios organizacionales que hacen parte de su especificidad (Álvarez, 2017) y que han sido desarrollados en todo el mundo con el impulso de su mayor ente de integración: la Alianza Cooperativa Internacional. Dichas especificidades dan cuenta de otras formas de hacer economía en las que se coloca en el centro de la actividad económica a los asociados y sus necesidades, y está sintonizada con la propuesta del institucionalismo económico contemporáneo (Alarcón, 2016).

Con esto, las reglas que orientan a la firma capitalista encuentran otras connotaciones en las cooperativas y, por tanto, la medición de estas empresas a partir de variables financieras tradicionales solo es la punta del iceberg de un entramado de valores que no encuentran referencias bajo los ránquines de competitividad empresarial, pero que sí repercuten al generar productos socialmente demandados en acuerdos internacionales como, por ejemplo, los Objetivos de Desarrollo Sostenible.

A partir de la necesidad de generar puentes de comunicación entre la valoración tradicional de las empresas y la valoración de las empresas cooperativas, primero se estima el peso absoluto y relativo específico- que tiene la economía cooperativa en las principales magnitudes agregadas económicamente significativas. Luego, se contrasta el crecimiento del cooperativismo en relación con el crecimiento del estándar material de vida — monetario— por habitante de la economía general, esto es, el PIB per cápita.
Lo anterior se trata en dos series temporales: 20032010 y 2010-2016. Estas corresponden a periodos de crecimiento económico del país, pero que para el cooperativismo tuvieron disímiles resultados, tal como se expone más adelante. En consecuencia, y como producto intermedio, se revisan y actualizan las cifras estimadas que en otros trabajos se han realizado para el cooperativismo colombiano (Alarcón, 2013), a fin de que, como producto final, se contribuya a los estudios relativos sobre la medición y la incidencia de las cooperativas en las cifras agregadas de cuentas nacionales.

El trabajo comienza con un apartado de fundamentos sobre el concepto de «economía social» en el que están inmersas las cooperativas, de modo que sitúa en él la medición del progreso material como la más trabajada, la cual es en la que se centra este trabajo. También se incorporan los fundamentos de la medición material monetaria a través de la contabilidad nacional.

Luego, se trata en este concepto cierta problemática e intentos de una medición diferente a la que se considera bajo las cifras agregadas económicamente significativas -sobre economía social y cooperativa- Continúa un apartado que da cuenta de la metodología general y de las fuentes que se van utilizar, así como algunas alternativas sobre estas.

Después se muestra el peso que tiene la economía cooperativa en las principales magnitudes económicas agregadas de Colombia, referidas al plano material-monetario de los sistemas de cuentas nacionales o SCN. Se prosigue con la exposición de ciertas limitaciones en la disponibilidad de fuentes de información sobre funciones sociales del cooperativismo colombiano, junto con un ánimo de convergencia en los apartados o ítems de las distintas alternativas de balance social.

Seguidamente, se presenta el resumen del circuito económico cooperativo a través de la sucesión de sus 
cuentas satélite, en perspectiva comparada con respecto al circuito económico nacional. Fruto del proceso anterior se introduce el papel de las cooperativas colombianas en la contabilidad del crecimiento económico, con lo que se muestra la descomposición del crecimiento de su producto por habitante y la influencia de la dinámica de la productividad del trabajo cooperativo en la de la economía nacional.
Así, se repasa la importancia de esos temas en un momento en el que el cooperativismo gana terreno como herramienta para la organización socioeconómica de territorios y su posible extensión a la evaluación del impacto de las políticas públicas asociadas, así como a la evaluación de las políticas de las cooperativas. La presentación de unas conclusiones finaliza el trabajo.

\section{Fundamentos conceptuales y cuentas satélite del cooperativismo: las cifras monetarias nos dicen algo}

as cooperativas se rigen por siete principios que
Jorientan su accionar en los mercados. Estos principios privilegian la autogestión que se expresa por medio de la responsabilidad de realizar aportes económicos, formarse para participar, decidir y operar sin prioridad de lucro personalista, bajo un engranaje organizacional que privilegia la operación entre cooperativas en el ámbito local y con orientación hacia la comunidad.

Por objeto social, las cooperativas están dedicadas a la producción de bienes y servicios dirigidos al beneficio de sus asociados y sus grupos de interés. Por tanto, Ward (1958) postulaba que la función objetivo de una cooperativa es maximizar los beneficios netos per cápita - en vez de los beneficios netos totales de las empresas capitalistas- - .

Esta particular orientación de sus propósitos, la dirección de la gestión y el destino de la actividad económica genera que los resultados organizacionales puedan ser medidos en términos convencionales como resultados financieros, comerciales $y$ de generación de empleo, así como por otros resultados que benefician a los asociados como dueños, gestores, trabajadores o usuarios de la actividad económica. Estos resultados se suelen expresar en los informes económico-financieros $y$, por tanto, se tiende a subestimar la incidencia cooperativa en sus grupos de interés.
En consecuencia, la idea de elaborar balances sociales complementaría la forma de visibilizar la incidencia en una idea de desenvolvimiento más integral que incluiría aspectos sociales y ambientales y que, conviene decir, resultan difíciles de medir material y monetariamente. Es decir, la sostenibilidad de los emprendimientos no se limita a la dimensión económica, sino que tiene que ver con un equilibrio de las tres dimensiones de la sostenibilidad que plantea Brundtland (1987).

Lo anterior propicia que el balance social sirva de herramienta para calcular la contribución de las cooperativas en la consecución de los Objetivos de Desarrollo Sostenible u ODS. A pesar de que los ODS son un desempeño nacional, agregado, pueden, con ciertos ajustes, servir de repositorio de unidades socioeconómicas micro al mostrar las prácticas que contribuyen al agregado (Álvarez y Alarcón, 2019).

El caso es que se han desarrollado herramientas de seguimiento institucional con el fin de rendir cuentas sobre el esfuerzo nacional para cumplir los ODS (ONU, 2018), pero no hay un registro de herramientas que permita identificar el aporte de organizaciones tales como las cooperativas que, a pesar de no estar articuladas con el Estado, desarrollan prácticas que contribuyen al cumplimiento de las metas de estos (OIT-ACI, 2014). De hecho, varias iniciativas logran desarrollarse por el accionar de cooperativas en ciertos 
territorios (CES-España, 2016; Salathé-Beaulieu, Bouchard y Mendell, 2019), sin que necesariamente estas se ajusten al cumplimiento vinculante de cualquier pacto, acuerdo o tratado.

Desde la perspectiva institucionalista de la economía social se consideran fundamentos de las cooperativas su hábito de no prioridad en el ánimo de lucro de finalidad personal o NPALP, y sus rutinas de emisión de transferencias sociales en especie o TSE (Alarcón, 2016). Por tanto, los resultados de las cooperativas orientadas a maximizar el beneficio neto per cápita se pueden estimar a través de las TSE ampliadas a las convencionales, siendo estas un término de las cuentas nacionales que implícitamente añadirían un valor social al puramente económico (Alarcón y Álvarez, 2018).

Lo anterior requiere una propuesta sobre la existencia de un valor agregado bruto o VAB económico y social o PIB económico y social. Téngase en cuenta que las TSE tendrían un único destino: los hogares. De ellas, las convencionales y, por definición, en todo SCN, solo pueden emitirse por administraciones públicas e instituciones sin fines de lucro al servicio de los hogares. Las TSE ampliadas las emitirían otras entidades de la economía social que no fueran solo entidades sin fines de lucro. Cabe destacar que las TSE ampliadas no expresan acciones de responsabilidad social corporativa asimilables a las de una empresa capitalista, las cuales se sitúan en otras transferencias corrientes, según los SCN.

Así, la pertinencia de tratar los agregados en este trabajo y los conceptos anteriores están estrechamente relacionados con las cuentas nacionales. Cuando estas se dedican especialmente a un segmento socioeconómico dentro del sistema, se habla de «cuentas satélite». Así, pues, estas confecciones son relativamente recientes — década y media - para las organizaciones cooperativas y se basan en una búsqueda de solventar los problemas relacionados con la confiabilidad de la información, también los relativos a su desagregación y su comparabilidad con el sistema económico general o con partes de este.

Pocos países han logrado generar información agregada para el conjunto de la economía social, entre los cuales se destacan Bélgica, Canadá, España y Portugal.

En España, por ejemplo, las estimaciones sobre la economía social se fechan para 2001, 2005 y 2008. Los dos primeros estudios de este tipo, publicados en 2005 y 2009, producen las cuentas dentro de un proyecto más abarcador que incluía, además de cooperativas, mutualidades, a las asociaciones y fundaciones, así como entidades singulares - Cruz Roja, Cáritas y Organización Nacional de Ciegos Españoles-ONCE-. El tercero se publica en el 2011, se produce en colaboración con el Instituto Nacional de Estadística de España y viene a ser congruente con el Manual para la elaboración de las cuentas satélite de las empresas de la economía social: cooperativas y mutuas publicado por Ciriec en el 2006, y presentado a petición de la Unión Europea en el 2009.

Otros países han desarrollado estudios de proximidad a partir de proyectos europeos ${ }^{3}$ sobre cuentas satélite de las cooperativas y mutuas que se concentran en Europa - pero sin la integración total del segmento no lucrativo de la economía social—. Se trata de los casos de Bélgica — fechado en el 2007—, Bulgaria — fechado en el 2010 - Serbia — fechado en el 2009- y la antigua República Yugoslava de Macedonia —estimaciones fechadas para el 2002, el 2008 y el 2010—.

La propuesta portuguesa se presenta en la primavera del 2013, fruto del protocolo de cooperación del 2011 entre el Instituto Nacional de Estadística portugués y la Cooperativa António Sérgio para la Economia Social, CIPRL (CASES) ${ }^{4}$, y las posteriores del 2013 y el 2016. Dispone de estimaciones de voluntariado dirigidas al 2012, pero no para las dos estimaciones siguientes,

${ }^{3}$ Específicamente, Véase al respecto https://ec.europa.eu/growth/content/satellite-accounts-cooperatives-and-mutuals_es

${ }^{4}$ Esto es, las cuentas satélite de la economía social para Portugal en el 2010. Véase https://www.cases.pt/contasatelitedaes/ 
e incluye, como los trabajos fechados en el 2001 y el 2005 para España, la cuenta consolidada del conjunto de entidades componentes de la economía social y, por tanto, las correspondientes al cooperativismo.

Buena parte de todos esos trabajos se han incorporado en un artículo de Chaves y Monzón (2017) que actualiza el realizado por los mismos autores en el 2011 y amplía la versatilidad del constructo de economía social.

El argumento central para el desarrollo de las cuentas satélite de las cooperativas es que en los SCN no aparece la desagregación de la actividad de este tipo de organizaciones (INE-Ciriec, 2014), las cuales destinan la mayoría de los excedentes a la consecución de objetivos a favor del desarrollo sostenible, la mejora de los servicios dirigidos a los miembros y al interés general en tanto no tienen una prioridad en el ánimo de lucro personal.

Ahora bien, el hecho de que las cooperativas no tengan una prioridad en el ánimo de lucro personal, no impide la búsqueda de un lucro de finalidad colectiva, el cual termina por distribuirse entre sus asociados por medio de las TSE (Alarcón, 2011). Cuando la TSE son producto de diferenciales salariales, de precios o tipos de interés respecto a las mismas referencias del mercado, se estaría hablando de «TSE ampliadas».

Existe, además, una parte difícilmente medible de los resultados cooperativos, pero registrable. Lo anterior es resultado de la polivalencia de actividades que generan las cooperativas para el beneficio de sus grupos de interés, por la cual se podrían identificar actividades con beneficios monetarios y otras con beneficios no monetarios.

Algunos de estos beneficios se constituyen en rutinas que terminan por ser TSE ampliadas, estrechamente relacionadas con la concepción institucionalista de la economía social y cooperativa (Álvarez y Alarcón, 2019). A saber (Álvarez, 2016):

- Liberación de recurso: Como, por ejemplo, los diferenciales frente a los precios de mercado que obtienen los cooperativistas por sus transacciones con ellas.
- Excedentes sociales: Tales como aquellos bienes y servicios que obtienen los cooperativistas por las acciones no monetarias - aunque potencialmente convertibles- que se realizan en su organización.

- Bienes preferentes o meritorios del cooperativismo: Como, por ejemplo, aquellos bienes y servicios —educación, salud, seguros- que obtienen los cooperativistas producto de las decisiones democráticas para maximizar su bienestar colectivo, aunque individualmente no estén dispuestos a pagar por ellos - p. ej., los beneficios derivados de los fondos sociales - y que terminan expresándose en bienes públicos no estatales.

Hemos precisado que la polivalencia de actividades de las cooperativas y el destino de los excedentes y la distribución ex-ante para fortalecer sus fondos sociales muestran la importancia socioeconómica de las cooperativas y no debe limitarse a indicadores traducidos a moneda o cuantitativos, como, por ejemplo, el VAB o el empleo. Se es consciente de esto, pero este trabajo se acota para la punta del iceberg: el valor económico y social del cooperativismo, centrado en el valor agregado cuantificable en moneda. Al respecto, Etxezarreta, Mendiguren, Díaz y Errasti (2018) proponen asignar un valor monetario a aspectos sociales que muchas veces son difícilmente convertibles a valor en unidades monetarias, pero lo proponen en la dimensión micro para unidades productivas. Además, la parcialidad del modelo poliédrico utilizado no permite a agentes externos actuar como árbitro en las funciones económicas y sociales de las organizaciones objeto de estudio.

De manera similar a la anterior propuesta, Bassi y Vincenti (2015) proponen el modelo SAVE o Social Added Value Evaluation como herramienta de respuesta a una lógica integral de la evaluación del impacto social que los autores señalan como micro, meso y macro delas organizaciones. Sin embargo, no plantean el problema de la agregación meso-macro del impacto general, con lo cual el modelo no puede evaluar ni el conjunto ni la aportación de las organizaciones componentes evaluadas, lo cual incluiría escalas de validez, fiabilidad y valoración —individual y de la posible agregación-. 
En esa misma perspectiva, Retolaza, San-José y Ruíz-Roqueñi (2015) proponen un informe o resultado único que sirva de instrumento de toma decisiones calculando el valor integrado - social y no social—, a la par de reputación empresarial. Además, para esto consideran el modelo poliédrico del valor social empresarial. En todo caso, lo hacen desde una perspectiva individual, que no es la que se sigue en este trabajo.

Otra vía de la estimación del excedente social es la resultante de las matrices del bien común (Felber, 2012), propuesta que ofrece consultorías tanto a empresas tradicionales societarias de lucro personalista como a instituciones de las administraciones públicas para su consecución. No obstante, la causalidad «de abajo a arriba» no considera, a priori, externalidades negativas. En conjunto, se trata de opciones centradas en la organización, pero con las mismas carencias que otras propuestas tangenciales sobre balance social o sobre sostenibilidad.

Por su parte, Díaz y Marcuello (2010) buscan relacionar la generación de empleo cooperativo y el ciclo económico — evolución cuatrimestral del PIB gobernado por la iniciativa de mercado y competitiva, pero señalan que no es concluyente. La referencia de estos autores se justifica en su conocimiento del tema y por el paralelismo de lo que ellos tratan en relación con los resultados de la descomposición del PIBpc, lo cual se expone en el último epígrafe de este trabajo. No es concluyente que el empleo cooperativo constituya un efecto refugio ante pérdidas de empleo de la economía general, y el caso es que tampoco crece el empleo cooperativo frente a un comportamiento negativo del ciclo; además, viene a ser más la causación acumulativa de la economía capitalista la que explicaría respuestas menos que proporcionales a crear VAB y empleo cooperativo ante ciclos expansivos y menores pérdidas relativas de ellos en ciclos recesivos.

Retomando la cuestión de las grandes cifras cooperativas, conviene insistir en que el tratamiento del cooperativismo no existe de manera explícita en los sistemas de cuentas nacionales o SCN. Aunque es menester precisar que considera uno de los componentes de la economía social: el tratamiento de las instituciones privadas sin fines de lucro al servicio de los hogares o IPSFLSH.

El trabajo de Bouchard y Rousselière (2015) aborda la consideración de una parte del cooperativismo dentro de las IPSFLSH, pues abarca dimensiones tales como la producción en sentido amplio, de S. Mertens y M. Marée, como una suma de la producción de empresas sociales y sus impactos directos, indirectos e inducidos. Algo de suma trascendencia, pero que se atribuye a las empresas sociales sin considerar los efectos negativos, de modo que quedan los efectos netos de externalidades positivas y negativas inconclusos.

Si se parte de que toda actividad económica y social no se puede medir y concebir en el SCN y, por tanto, no es posible obtener el peso del conjunto materialmonetario junto con su extensión social mediante unas cuentas satélite, conviene reflexionar lo siguiente: los resultados monetarios enriquecen y permiten un mayor acercamiento a la realidad integral — social y ambiental — de las cooperativas.

Por esta razón, los números sí nos hablan de las cooperativas siempre que se añada la parte social — sea convertible a moneda o no, pero concretada en otros indicadores extendidos - y la ambiental. Esto conecta con una propuesta de complementar el resumen de las grandes cifras en términos de valor monetario con los balances sociales de las entidades a un nivel de conjunto, en consideración a las externalidades que suman y restan al conjunto de sus funciones.

Se pasa ahora a acotar espacialmente los resultados de este trabajo, referidos a la estructuración de unas «cuentas satélite» del cooperativismo en Colombia. Los primeros intentos por desarrollar herramientas orientadas a medir las magnitudes del sector cooperativo fueron propuestos en la década de los ochenta con el Plan de Desarrollo Cooperativo o Plandecoop. Posteriormente, entrada la década de los noventa, Rodríguez (1993) realizó un primer acercamiento a partir de su tesis de grado. 
Durante el inicio del presente siglo, la entidad encargada de recoger la información estadística —el DANE - introdujola noción de instituciones sin fines de lucro o ISFL, las cuales clasificó en instituciones de mercado y de no mercado y en instituciones sin fines de lucro que sirven a los hogares o ISFLSH, instituciones sin fines de lucro financiadas por el gobierno e instituciones sin fines de lucro que sirven a las empresas o ISFLSE (DANE, 2005), propias del Sistema de Cuentas Nacionales de Naciones Unidas. Posteriormente, Bernal (2008) amplía la idea estudiada en 1998 sobre una planificación macroeconómica del sector cooperativo utilizando como instrumento un modelo insumo-producto, y en el 2013 Cenicoop desarrolla un proyecto denominado Impacto Social y Económico del Cooperativismo Colombiano (Cenicoop, 2015).

En el 2016 se reanudan las discusiones en el marco de las propuestas de reforma tributaria. El Consejo Técnico de la Contaduría Pública precisa para el Sistema de Cuentas Nacionales, auspiciado por Naciones Unidas, que las entidades sin ánimo de lucro o ESAL se clasifican como «unidades institucionales, que están en condiciones, por derecho propio, de poseer bienes y activos, incurrir en obligaciones e involucrarse en actividades económicas y transacciones con otras unidades y por tanto poseen particularidades que deben ser estudiadas de manera diferenciada» (Franco, Sarmiento, Serrano y Suárez, 2015). También se publica el libro Medición socioeconómica del impacto del cooperativismo (Rodríguez, Sánchez, Álvarez y Fajardo, 2016), en el cual se plantea, sin desarrollarlo, un análisis comparado de las cuentas satélite con las cuentas nacionales mediante la identificación de la participación y el comportamiento del valor agregado cooperativo, la forma como se genera el ingreso y la representatividad de los impuestos sobre su valor agregado.

Para finalizar el apartado, una aportación diferente pero complementaria a la que se trata aquí para la economía cooperativa de Colombia es la de Alarcón y Álvarez (2018), en la que se extiende el conocimiento sectorial del cooperativismo colombiano a las redes de relaciones cooperativas intersectoriales y se da cuenta de cómo la causalidad acumulativa es diferente a la del conjunto de la economía, en la cual se encuentra mayoritariamente la participación de las entidades de lucro personalista.

\section{Metodología y fuentes estadísticas}

\begin{abstract}
$\mathrm{A}^{\mathrm{n}}$ fin de lograr el objetivo de estimar el peso absoluto y relativo que tiene el cooperativismo en las principales magnitudes agregadas de la economía colombiana, mediante el cual se obtiene el saldo de la cuenta de producción, el VAB o el PIB del cooperativismo, se realiza un levantamiento y un procesamiento de la información contable que las cooperativas colombianas reportan ala Confederación de Cooperativas de Colombia o Confecoop, junto con información similar de la Superintendencia de Economía Solidaria y las distintas superintendencias, como, por ejemplo, la Financiera, de Vigilancia, de Servicios, o de Salud y Vigilancia.
\end{abstract}

Con esto se realiza la estimación posterior de agregados a partir de la información de entidades empresariales de la Encuesta Anual Manufacturera del DANE, así como informes anuales de gestión, informes de coyuntura empresarial, informes de dinámica empresarial, boletines y noticias de Confecámaras ${ }^{5}$. Por otra parte, para los ajustes en las variables de empleo y salario medio se hace uso de la Encuesta Continua de Hogares y la Gran Encuesta Integrada de los Hogares para las secciones de Fuerza Laboral, Seguridad Social y Sexo (Alarcón, 2013).

\footnotetext{
${ }^{5}$ Véase www.confecamaras.org.co
} 
Para esa construcción se homogeneizan los estados financieros a las cuentas que se conforman en los manuales de SCN (Alarcón, 2013; ONU, 1993; 2008) utilizando la Clasificación Internacional Industrial Uniforme Revisión 3 o CIIU Rev. 3. Las entidades cooperativas se clasificaron de acuerdo con su mayor ingreso operacional. Además, se hace referencia al Manual para la elaboración de las cuentas satélite de las empresas de la economía social: cooperativas y mutuas, elaborado por el Ciriec (Barea y Monzón, 2006) como una herramienta más en el proceso.

Con las referencias anteriores se elevan las cifras y se corrigen las operaciones que pertenecen a cada cuenta del SCN. Es decir, se trata la congruencia ${ }^{6}$ de las cuentas agregadas para la muestra del cooperativismo a las de la población de cooperativas (Figura 1).
La evolución destaca un crecimiento desde las poco más de 5100 cooperativas en el 2003 hasta un máximo de unas 8550 en el 2010, ocasionado por el incremento de cooperativas de trabajo asociado, o CTA, fomentadas por organismos del Estado y luego liquidadas en los años sucesivos por las inspecciones realizadas (Álvarez y García-Müller, 2013); hasta normalizar el número de cooperativas que alcanzan casi 3670 en el 2016.

Una vez obtenidos los agregados del cooperativismo, se descompone el PIB por habitante de Colombia, así como el de su crecimiento, tanto en ciertas etapas como por indicadores componentes que incluyen indicadores de referencia cooperativa. Estos incluyen, a su vez, el empleo y el VAB cooperativo a fin de relativizarlos con respecto a la economía de Colombia.

Figura 1. Población de cooperativas en Colombia durante el periodo 2003-2016

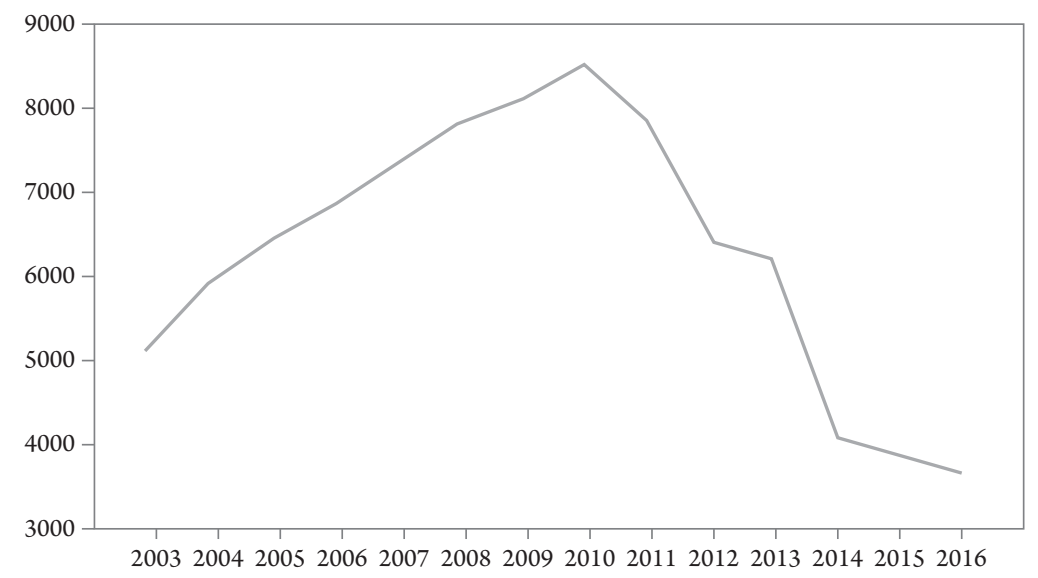

Fuente. Elaboración propia con base en datos de Confecooop, Superfinanciera, Supevigilancia, Superservicios, Saludcoop, Acemi, Gestar Salud y DANE.

\footnotetext{
${ }^{6}$ Los factores de elevación y congruencia los constituyen ratios del número de referencia de la muestra sobre la población de manera desagregada buscando una iteración que permita obtener la congruencia de las elevaciones de grupos y de total, no superior o inferior, $\infty i$ $=($ Variable Muestra/Variable Población)i.
} 
Con estos indicadores es posible describir el circuito económico agregado del cooperativismo (Alarcón, 2013). Como resultado, se elabora una correspondencia entre magnitudes del SCN y las rúbricas del sistema de contabilidad empresarial de Colombia, con la cual se consigue agregar $y$, luego, corregir por ciertos factores de elevación y de congruencia hacia la población cooperativa.

La última parte del método que sigue este trabajo se centra en la denominada «contabilidad del crecimiento». Esta se configura a través de la descomposición del PIB por habitante y la de su crecimiento en indicadores absolutos y relativos del cooperativismo, tales como la productividad aparente cooperativa - a fin de compararla con la total de la economía - o el peso del empleo cooperativo sobre el empleo total.

El PIB por habitante o PIBpc es un indicador relativo al estándar material de vida, a diferencia del PIB que es absoluto. Permite la comparación directa con terceras economías a través de una medida indirecta del estándar de vida material debido a que entiende cómo cuanto mayor sea la capacidad económica por habitante mayor será el estándar material de vida de la población en términos de media en valor monetario 一expresión 1-.

$$
\text { PIBpc }=f \text { (componentes económicos, }
$$

componentes de mercado laboral, componentes

$$
\text { demográficos) [1] }
$$

En primer lugar, se encuentran los componentes económicos representados por la productividad aparente del trabajo o PAT, obtenida como resultado del PIB entre la población ocupada o PIB/PO. Por otra parte, se muestran indicadores del mercado laboral y demográfico, representados por la tasa de empleo sobre la población —PO/Población — en la expresión 2.

$$
\text { PIBpc }=P I B / P O x P O / \text { Población }[2]
$$

Sise incluye elVAB — PIB — cooperativo, la expresión descompone el PIBpc en la inversa del peso del sector cooperativo en el PIB nacional —PIB/VABc- la productividad aparente del cooperativismo - VABc/ Empleoc-, la participación del empleo cooperativo entre el empleo total de la economía -Empleoc/ Empleo-y la ratio del empleo de la economía entre la población total -Empleo/Población- que se muestran en la expresión 3.

$$
\begin{gathered}
P I B p c=P I B / V A B c \times V A B c / \text { Empleoc } x \\
\text { Empleoc/Empleo } \times \text { Empleo/Población [3] }
\end{gathered}
$$

De manera que la diferencia relativa del PIBpc en dos momentos del tiempo, su crecimiento, se descompondrá, aproximadamente, en la suma de las aportaciones al crecimiento de los componentes del PIBpc — suma de las multiplicaciones de cada componente por un factor derivado del diferencial que genera el concepto a descomponer-, tal que $\triangle P I B p c \approx$

$$
\begin{gathered}
\approx \Omega^{1} P I B / V A B c+\Omega^{2} V A B c / \text { Empleoc }+ \\
\Omega^{3} \text { Empleoc/Empleo }+\Omega^{4} \text { Empleo/Población }
\end{gathered}
$$

En la expresión 4, cada $\Omega i$ es la aportación al crecimiento de cada componente i de la expresión. Como las aportaciones al crecimiento de cada componente del PIBpc, $\Omega i$, no suman exactamente el crecimiento del PIBpc debido a las transformaciones que requiere el crecimiento relativo de cada componente - la suma de las variaciones relativas de cada componente por cada punto de la ratio respectiva de cada componente $\mathrm{i}-$, se aplicará un factor de ajuste, $\partial i$, a cada componente, que será la ratio entre el crecimiento efectivo del PIBpc de la economía entre la suma de las aportaciones iniciales, $\Omega i$, tal que:

$$
\partial i=[\Delta P I B p c / \Sigma i \Omega i][5]
$$

\footnotetext{
${ }^{4}$ En Argentina, la educación superior está comprendida por la educación universitaria y terciaria. Esta última se desarrolla en institutos de educación superior o universidades, tiene una duración de entre seis meses y tres años, y está orientada a títulos «técnicos», no profesionales.
} 
Como acotación final, debido a que existen entidades que no hacen un reporte continuo de sus estados financieros, se seleccionaron las entidades que sí reportan continuamente en un año o en dos o más periodos seguidos. Las entidades que tienen vacíos en sus reportes no se tuvieron en cuenta.

\section{Importancia del sector cooperativo en la economía colombiana en las estimaciones más recientes}

\begin{abstract}
Con la información disponible para la economía colombiana del DANE, la Confederación de Cooperativas de Colombia o Confecoop, la Confederación Colombiana de Cámaras de Comercio o Confecámaras y las estimaciones resultado de Alarcón (2013), el segmento cooperativo de la economía colombiana lo constituyen, en el 2016, casi 3700 entidades que remuneran a unos 54200 asalariados y dan trabajo a casi 192350 empleos dependientes y no dependientes, que generan un valor añadido anual de casi 4,3 billones -entendido como millones de millones- de pesos colombianos, en números redondos (Tabla 1).
\end{abstract}

Eso viene a suponer, por una parte, cerca del $0,3 \%$ de las sociedades consideradas como activas en Colombia a tenor de las cifras deducidas de las informaciones de Confecoop y la Encuesta Anual Manufacturera del $\mathrm{DANE}^{7}$. Por otra parte, el sector cooperativo colombiano representa casi medio punto porcentual del empleo asalariado en Colombia, proporción que se acerca al $1 \%$ si se considera relativamente al empleo total, es decir, a los ocupados, que incluyen iniciativas no societarias. De forma paralela, el PIB cooperativo -valor agregado bruto con el ajuste de los impuestos netos a la producción- alcanza casi el $0,6 \%$ del nacional, iniciándose en el 2003 en 0,9, que alcanza 1,8 puntos de participación en el 2010 (Tabla 1).

\footnotetext{
${ }^{7}$ No existe para Colombia un registro numérico que desagregue información susceptible de uso distinto al uso comercial, de negocios o relacional, lo cual provoca que los estudiosos no sepan con exactitud cuántos emprendimientos, de qué tipo y en qué situación legal puedan encontrarse. La posibilidad de obtener esa información se pide en las Cámaras de Comercio — véase www.confecamaras.org.co/ index.php/directorio-de-camaras—, pero no de manera integrada. La otra opción es la que se sugiere aquí: promediando los datos de las fuentes de información a partir de indicadores indirectos, como puede ser, por ejemplo, el Índice de Densidad Industrial producido por el DANE y las informaciones ofrecidas puntualmente, en informes o estudios, sobre los emprendimientos nacionales y su dinámica.
} 
Tabla 1. Magnitudes del cooperativismo en Colombia, 2003-2016

\begin{tabular}{|c|c|c|c|c|c|c|c|}
\hline & 2003 & 2010 & 2014 & 2016 & $\underset{(7)}{2003-2010}$ & $\underset{(7)}{2010-2016}$ & $\begin{array}{c}2003- \\
2016^{(7)}\end{array}$ \\
\hline Cooperativas $^{(1)}[\mathrm{a}]$ & 5107 & 8533 & 4088 & 3666 & 7,6 & $-13,1$ & $-2,5$ \\
\hline $\begin{array}{l}\text { Entidades totales activas } \\
\text { (2) }[\mathbf{b}]\end{array}$ & 1325276 & 2267190 & 2595533 & 2762774 & 8,0 & 3,3 & 5,8 \\
\hline Sociedades $^{(3)}$ & 934620 & 1138915 & 1228688 & 1277626 & 2,9 & 1,9 & 2,4 \\
\hline$[\mathbf{a}] /[\mathbf{b}]$ en \% & 0,39 & 0,38 & 0,16 & 0,13 & & & \\
\hline $\begin{array}{c}\text { Asalariados en } \\
\text { cooperativas }^{(1)}[c]\end{array}$ & 80987 & 139703 & 69690 & 54196 & 8,1 & $-14,6$ & $-3,0$ \\
\hline Asalariados totales $^{(4)}[\mathbf{d}]$ & 8497983 & 9750474 & 11611329 & 11963837 & 2,0 & 3,5 & 2,7 \\
\hline$[\mathbf{c}] /[\mathbf{d}]$ en \% & 0,95 & 1,43 & 0,60 & 0,45 & & & \\
\hline $\begin{array}{c}\text { Ocupados en } \\
\text { cooperativas }^{(1)}[\mathrm{e}]\end{array}$ & 266820 & 537232 & 247318 & 192330 & 10,5 & $-15,7$ & $-2,5$ \\
\hline Ocupados totales $^{(4)}[\mathbf{f}]$ & 15675381 & 18129156 & 21503323 & 22156141 & 2,1 & 3,4 & 2,7 \\
\hline$[\mathbf{e}] /[\mathbf{f}]$ en $\%$ & 1,70 & 2,96 & 1,15 & 0,87 & & & \\
\hline VAB cooperativas $^{(1)}[\mathbf{g}]$ & 2076236 & 855421 & 5983072 & 4268607 & 22,4 & $-10,9$ & 5,7 \\
\hline VAB total $^{(5)}[h]$ & 249155000 & 489236000 & 693318000 & 768761758 & 10,1 & 7,8 & 9,1 \\
\hline$[\mathrm{g}] /[\mathrm{h}]$ en \% & 0,83 & 1,75 & 0,86 & 0,56 & & & \\
\hline $\begin{array}{c}\text { Remuneración de } \\
\text { asalariados cooperativas } \\
(1)[\mathbf{i}]\end{array}$ & 1368896 & 6466380 & 3413193 & 2435134 & 24,8 & $-15,0$ & 4,5 \\
\hline $\begin{array}{c}\text { Remuneración de } \\
\text { asalariados total }^{(5)}[\mathbf{j}]\end{array}$ & 77610000 & 151115000 & 250724000 & 285865984 & 10,0 & 11,2 & 10,5 \\
\hline$[\mathbf{i}] /[\mathbf{j}]$ en $\%$ & 1,76 & 4,28 & 1,36 & 0,85 & & & \\
\hline TSE cooperativas $^{(6)}[\mathbf{k}]$ & 170346 & 524560 & 543043 & 608776 & 17,4 & 2,5 & 10,3 \\
\hline TSE totales $^{(5)}[1]$ & 17826000 & 39458000 & 58841000 & 68982232 & 12,0 & 9,8 & 11,0 \\
\hline$[\mathbf{k}] /[1]^{(8)}$ en \% & 0,96 & 1,33 & 0,91 & 0,87 & & & \\
\hline
\end{tabular}

Fuente. (1) ConfecoopyAlarcón (2013).(2) Confecámarasy Encuesta Anual Manufacturera delDANE. (3) Confecámaras, Informes anuales de gestión, informes de coyuntura empresarial, informes de dinámica empresarial, boletines y noticias, recuperados de en www.confecamaras.org.co. (4) Encuesta Continua de Hogares y Gran Encuesta Integrada de los Hogares, para las secciones de Fuerza Laboral, Seguridad Social y Sexo. (5) Cuentas Nacionales Anuales del DANE. (6) Estimación como producto de los asalariados de las cooperativas por el diferencial salarial. (7) Tasa de Crecimiento Media Anual Acumulativa. Para el VAB, remuneración de asalariados y TSE se resta la inflación media anual acumulativa, según las series del deflactor del PIB del DANE. (8) Relativamente a las TSE nacionales junto con las estimativas de las cooperativas, de forma que el indicador termine correspondiendo a una proporción como parte del total. 
Los números presentados en la tabla 1 evidencian una evolución en forma de pico, escalando desde el 2003 hasta alrededor del 2010, para luego caer de manera progresiva hasta el 2016, que es el último dato que se puede extrapolar desde fechas en las que se conocen fuentes homogéneas con las que sea posible analizar el comportamiento dinámico del cooperativismo en Colombia.

La expansión del sector cooperativo colombiano entre el 2003 y el 2010, así como la posterior recesión entre el 2010 y el 2016, encuentran un reflejo ejemplar en el desempeño de las cooperativas de trabajo asociado o CTA. Estas, en el último periodo, sufren la liquidación de un número importante, con la consecuente disminución en las cifras correspondientes al VAB $y$ al empleo, en un contexto de profusos marcos regulatorios. El caso es que desde finales de la década de los noventa y hasta mediados de la década del 2000 se constituyeron miles de CTA en un entorno de expansión económica, apertura comercial y profundización de las políticas de desregulación laboral (Bedoya y Caruso, 2006; Farné, 2008, Álvarez y García, 2013) (véase la Figura 2).

Figura 2. Cooperativas de trabajo asociado en Colombia, 1983-2016

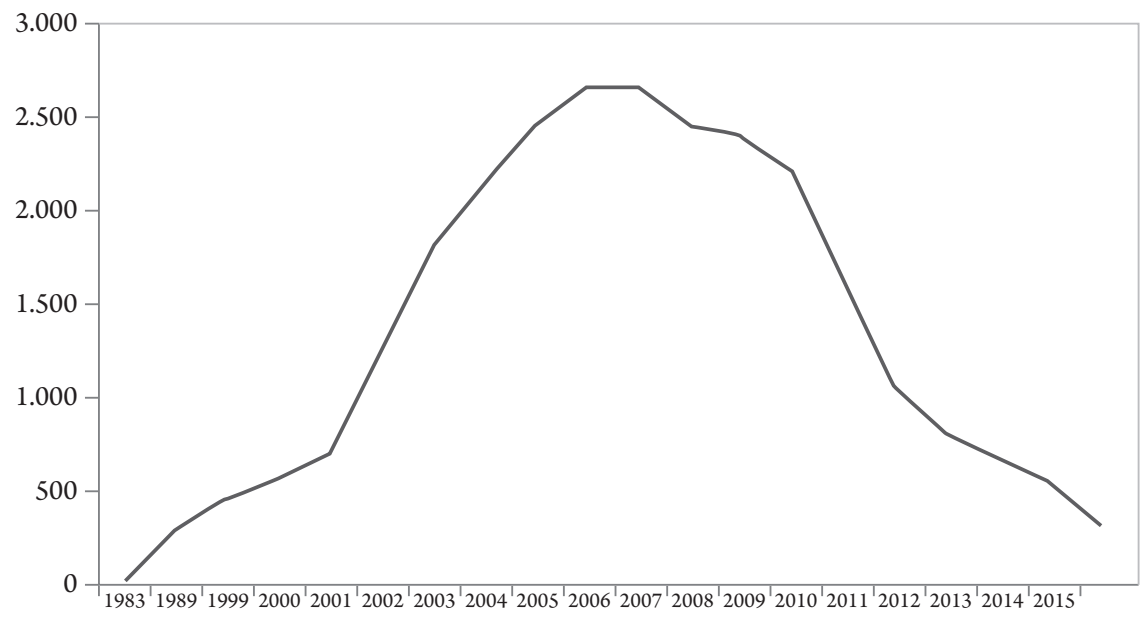

Fuente. Elaboración propia con base en datos de la Superintendencia de la Economía Solidaria.

Las organizaciones cuya creación fue producto de la autoorganización de trabajadores terminó por ser minoría ante el boom de cooperativas creadas para ser instrumentalizadas. Con esto el trabajo asociado, originalmente organizado para la producción y la autogestión, adquirió un matiz de servicio a terceros que contrataban la prestación de servicios.

La alerta realizada sobre la instrumentalización de nuevas cooperativas terminó por copar los titulares de medios de comunicación, en los que se generalizaron las noticias sobre prácticas indebidas a todo el subsector de CTA, lo cual sirvió de justificación para la emisión de resoluciones por parte de la administración pública para limitar la contratación con estas entidades. De acuerdo con Farné (2008), a esto se sumaban las presiones sindicales y las provenientes de los negociadores de tratados de libre comercio con el país, quienes coincidían en generalizar que las CTA contribuían a la precarización e intermediación laboral.

Lo anterior explica que la participación de las CTA en las grandes cifras del sector cooperativo se reduce sustancialmente, de modo que el sector cooperativo termina perdiendo casi un tercio del número de sus entidades entre el 2003 y el 2016 (Tabla 1), y, así, de la participación de las TSE derivadas de las diferenciales salariales cooperativas con respecto al salario medio colombiano. Es por esto que en este contexto adverso las CTA existentes entre el 2010 y el 2016 se encontraron ante un entorno hostil para su actuación 
en el mercado, en el que el cálculo del cumplimiento del objeto social se redujo a un conjunto de indicadores financieros basados en dictámenes legales de asimilación de las CTA a las empresas capitalistas, perdiéndose, por tanto, las ventajas cooperativas.

Algunas CTA buscaron mimetizarse mediante el desarrollo de prácticas similares a las de sus pares capitalistas. Otras se transformaron y, en muchos casos, profundizaron su alejamiento de los principios cooperativos. Tras la desnaturalización de las CTA se arrastró al sector cooperativo a una situación de desconexión con el desarrollo de circuitos económicos, enfatizando su actividad en el sector financiero, y a esto se le sumó la intervención de la principal cooperativa del país en términos de ingresos, excedentes e inversión: Saludcoop.

Finalmente, los sectores productivos en los que el cooperativismo se especializa respecto a la economía colombiana son los que tienen los mayores pesos en los mismos sectores de la economía nacional, y resultan ser los de las cooperativas de mayor tamaño, más intensivos en trabajo y que aumentan su tamaño. Se trata de una estrategia diferente a la de la entidad tradicional capitalista societaria que reduce relativamente su tamaño, aumentando la combinación capital-trabajo.

\section{Descripción del circuito económico agregado del cooperativismo colombiano}

$\mathrm{L}^{2}$ a tabla 2 representa de forma encadenada los saldos y las operaciones primordiales de las principales cuentas conjuntas del sector cooperativo en Colombia en el 2003, el 2010 y el 2014, desde la producción total hasta llegar a la capacidad o necesidad de financiación que tiene el cooperativismo colombiano frente al resto de los sectores de la economía. En principio, la economía cooperativa colombiana generó, en el 2014 -2003 y 2010 en adelante entre guiones, respectivamente- una producción total de 16,3 - 6 y 21,3- billones de pesos, totalmente «producción de mercado $\gg^{8}$.

Retomando la información de la tabla 1, del apartado anterior, conviene apuntalar la idea según la cual las TSE ampliadas que libera el cooperativismo colombiano son un indicador aproximado de la incidencia cooperativa. Son casi 610000 millones, en una estimación preliminar, derivados de una liberación de recursos por la existencia de diferencias salariales, por rama productiva, respecto a la economía general, y que participan de casi el 0,9\%, y que llegaron al 1,3 en el 2010 de las estimadas para Colombia por las cuentas nacionales del DANE.

$\mathrm{Su}$ crecimiento es de más de un $10 \%$ en el periodo considerado, muy cerca del crecimiento del $11 \%$ correspondiente a las que cuantifican el término de cuentas nacionales, relativo a cierta empatía social o bienes preferentes prestados por el sector público y las instituciones sin fines de lucro al servicio de los hogares.

La «producción no de mercado» del cooperativismo —543 000 millones de pesos en el 2014, 170000 en el 2003 y 525000 en el 2010 — viene a suponer entre el 2 y el $3 \%$ de las del conjunto de las administraciones públicas colombianas durante los años señalados, según la información que proporcionan las cuentas nacionales del DANE. Suponen en torno al $7 \%$ del PIB cooperativo.

\footnotetext{
${ }^{8} \mathrm{La}$ «producción de mercado» es la que se destina a ser vendida a precios que compensen sus costes. La «producción no de mercado» es la que se suministra a otras unidades institucionales — normalmente, a los hogares — de forma gratuita o a precios no significativos, entendiendo por tales aquellos que no cubren siquiera los costes incurridos: son la contrapartida contable de las TSE.
} 
Tales TSE ampliadas del cooperativismo no se han tenido en cuenta en las estimaciones preliminares de las cuentas satélite, pues se trata de estimaciones de lo que aporta el sector cooperativo como resultado de los diferenciales salariales medios del cooperativismo respecto a la economía nacional.

Para que el cooperativismo colombiano generara en el 2014 una producción total de 16,3 billones de pesos, casi en su totalidad «producción de mercado», debió efectuar - es lo que refleja la cuenta de producciónconsumos intermedios por valor de $10,4-3,9$ y 13 - billones de pesos, que suponen casi $2 / 3$ de sus empleos totales. El resultado - la diferenciarevela un valor añadido bruto generado - a precios de mercado- de algo más de 5,9 billones de pesos -2_, que representa, según se vio en el tabla 1 , poco más del 9,1 -0,96 y 1,7 - por 100 del VAB de la economía colombiana.

Este valor añadido a precios de mercado es la diferencia entre la producción total y los consumos intermedios empleados en los distintos procesos productivos a lo largo de un año, así como por una igualdad contable de la contabilidad nacional expresa la suma de la retribución de los factores que han contribuido a su obtención, esto es, la remuneración de los asalariados y el excedente de explotación.

Esta suma de excedente bruto de explotación -y rentas mixtas, al que se podría sumar el excedente social de las TSE ampliadas- del cooperativismo colombiano es el saldo contable de la genérica cuenta de explotación —la parte del valor añadido a coste de factores que no es remuneración de asalariados-, y asciende, en el 2014 a 2,13 -2003 y 2010 respectivamente 0,6 y 1,7 - billones de pesos, casi un tercio del valor añadido bruto del cooperativismo. El resto es remuneración de los asalariados, de lo que se deduce una diferencia fundamental con el conjunto de la economía colombiana: la proporción es mucho más paritaria entre ambas, es decir, la remuneración de los asalariados por encima y el excedente bruto de explotación - junto con las rentas mixtas- por debajo de las participaciones porcentuales del VAB.
Los ajustes contables reflejados en la cuenta de distribución secundaria de la renta y en la de redistribución de la renta en especie permiten llegar a la renta disponible ajustada bruta del cooperativismo. Destacan, expresadas en números redondos en los siguientes párrafos, dos partidas, principalmente: dentro de los recursos, las transferencias corrientes, casi 26000 millones de pesos en el 2010 — cerca de 7900 - que no constituye una fuente básica de financiación en las entidades cuyas actividades se dirigen a la venta al mercado; en los empleos, 460000 millones de pesos en transferencias corrientes diversas, las TSE; 543000 millones de pesos $-170000 \mathrm{y}$ 520000 - expresión de lo que el sector le devuelve a la sociedad en forma de transferencia social, también a su cargo pero no reflejadas; e impuestos directos, que rondaría los 115000 millones de pesos en el 2014. La renta disponible bruta asciende a poco más de 1,6 billones de pesos —440 000 millones de pesos y poco más de 1 billón- que se convierten en renta disponible ajustada por 1,06 billones de euros -270000 y 510000 millones de pesos-.

El saldo, esto es, la renta disponible ajustada bruta del cooperativismo, refleja — en ausencia de consumo corriente- lo que este destina al ahorro en términos brutos y, descontado el consumo de capital fijo, en términos netos. Así, el ahorro neto del cooperativismo — saldo de la cuenta de utilización de la renta disponible - en el 2014 supera los 1,3 billones de pesos - 370000 y 800000 millones de pesos-.

Este ahorro neto, incrementado con las transferencias netas de capital que recibe el cooperativismo sirve para financiar su formación bruta de capital —o inversión real-: 600000 millones de pesos $-160000 \mathrm{y}$ 500000 - Una cifra exigua si se pone en relación con la del total de la economía colombiana en el 2014, casi los 200 billones de pesos — 51 y 120 billones-, al no alcanzar el 0,3\% de la inversión real nacional.

Esto muestra, de nuevo, una característica propia del sector cooperativo: sus tasas de formación de capital -de inversión real-sobre el PIB son mucho menos de la mitad que las nacionales, casi el $10 \%$ - 6 y $8 \%$ frente a las de más del $25 \%$ nacionales. Lo anterior, 
con los consecuentes efectos de la innovación tecnológica polarizados en ambos ámbitos, favorables a la economía cooperativa y lucrativa de finalidad personal, respectivamente.

El saldo final de las cuentas corrientes para el cooperativismo colombiano, el de la cuenta de adquisición de activos no financieros, termina en una capacidad de financiación de 600000 millones de pesos — 150000 y 220000 - una vez cubiertas las necesidades de formación de capital de la economía cooperativa.

Así, los sectores productivos cooperativos no contribuyen de la misma forma al saldo final, el sector agrario es deficitario - endeudamiento neto o necesidad de financiación - en el 2003, y pasa de unos números rojos de -120 000 millones de pesos a un superávit - préstamo neto al resto - de unos 7000 millones en el 2010. En el mismo periodo, la rama productiva minera mantiene un préstamo neto de unos 16000 millones que se reduce a unos 2700; la manufactura, con altibajos, inicia el periodo con un préstamo — capacidad de financiaciónde 740000 millones de pesos y lo termina con endeudamiento, por -84000 . suministros de energía, agua y electricidad es deficitario financieramente con altibajos: de -378 millones pesos en 2003 a -457 en 2010; así ocurre también con la rama de transporte y comunicaciones, que lo es en mayor magnitud al reducir su endeudamiento neto desde -600000 millones de pesos a cerca de los -36900 .
El sector de educación, salud y otros servicios, que reduce su endeudamiento de -370000 a un préstamo de cerca de los 34300 millones de pesos. Esas dos últimas ramas productivas actúan de manera opuesta al sector de la construcción cooperativa, que inicia un préstamo neto de poco más de 310000 millones de pesos para terminar con un endeudamiento neto de casi -4800 millones.

Dos ramas cooperativas se destacan por la magnitud de sus cambios en la posición de prestamista o deudor neto entre la etapa señalada: comercio y hotelería e intermediación financiera. Mientras que estas cambian de un préstamo neto de 2 billones a un endeudamiento de casi 220000 millones pesos, el endeudamiento de aquellas es de casi 2 billones, y se convierte en 2010 en un préstamo neto de casi 400000 millones de pesos.

Así, los sectores productivos que más peso cooperativo mantienen, tanto en la economía nacional como en concentración cooperativa, han sufrido vaivenes en el saldo que resume su posición financiera neta, en la sucesión de los saldos de sus cuentas corrientes. De tal manera que la situación del préstamo neto cooperativo obtenido en el 2010 viene a ser gracias a la contribución de las ramas de comercio y hotelería, mientras que el conseguido en el 2003 es apuntalado por la aportación de la intermediación financiera.

La rama de actividades inmobiliarias y servicios a empresas, sin tener un peso específico notable ni en la economía nacional ni en su concentración en el conjunto cooperativo, contribuye netamente a ambas capacidades de financiación con la misma persistencia en la etapa de estudio. 


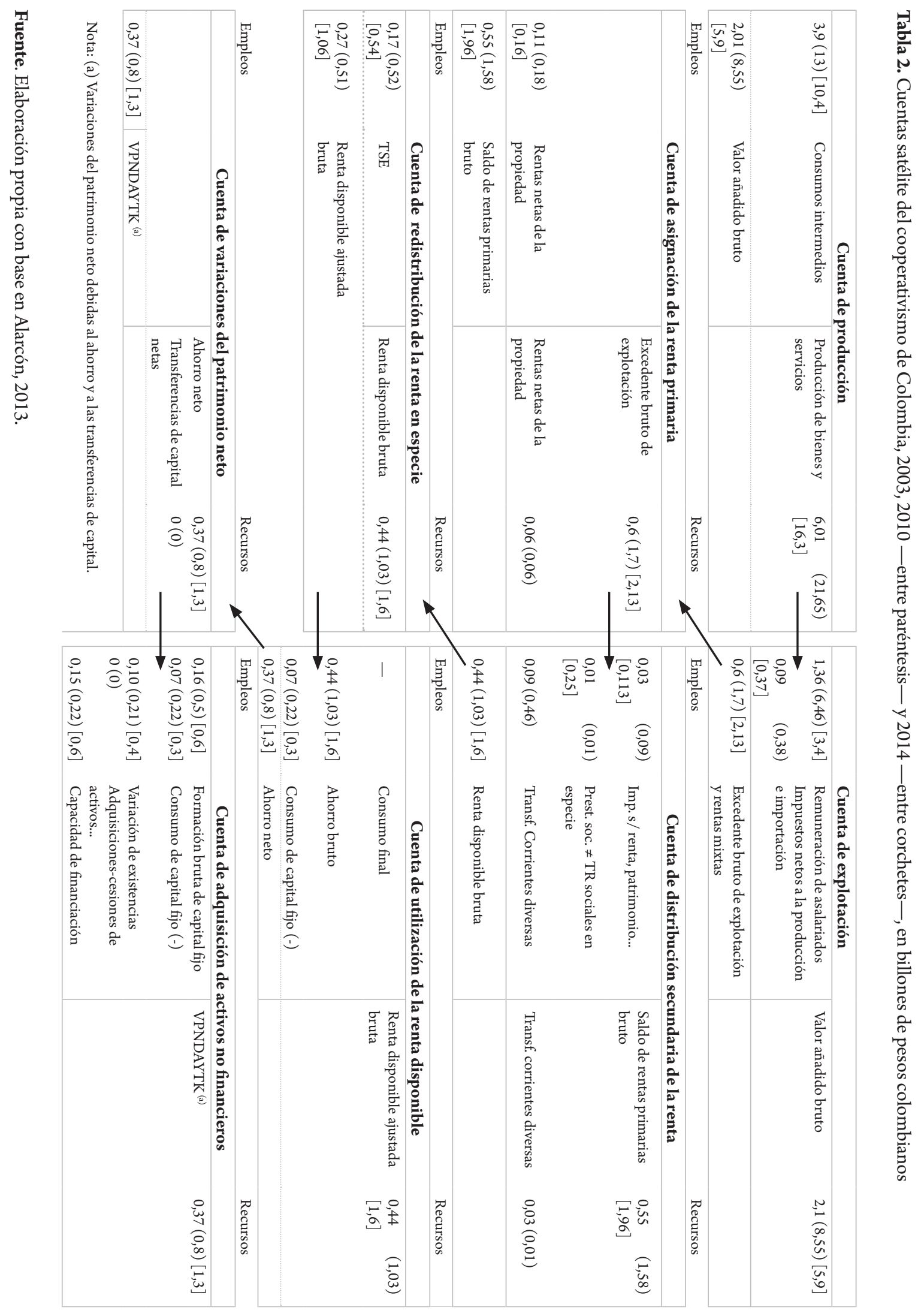




\section{Contabilidad del crecimiento del estándar material de vida, en valor monetario, de Colombia}

T a construcción de los datos macroeconómicos del cooperativismo colombiano implica contar con fuentes estadísticas. Esto es posible desde el 2003, cuando las cifras comienzan a presentarse de forma periódica. No obstante, y aunque desde el 2015 se pierde la consolidación estadística, a partir de proyecciones es posible también suplir la ausencia estadística para el 2016 y años posteriores.
Se ha dispuesto una desagregación en dos periodos: 2003-2010, cuando el cooperativismo alcanza su máxima expansión, y 2010-2015, iniciado por un punto de inflexión que encuentra su explicación en el desmonte progresivo de las cooperativas de trabajo asociado y la intervención de cooperativas que antes fueron preponderantes en las cifras, como es el caso de las cooperativas de salud y en especial de Saludcoop, intervenida en el 2011.

Tabla 3. Aportaciones al crecimiento del PIBpc de Colombia, incluyendo el cooperativismo, 2003-10 y 2010-15

\begin{tabular}{|c|c|c|c|}
\hline \multicolumn{2}{|c|}{$\Omega_{\mathrm{i}}$ en tasas de crecimiento medio porcentual anual acumulativo (TCMAA) } & $2003-2010$ & $2010-2015$ \\
\hline \multirow{2}{*}{$\begin{array}{c}\text { PIB per cápita } \approx \\
\approx(\text { PIB/Población })(1)+(2)+(3)+(4) \\
+(5)+(6)\end{array}$} & PIB por habitante nominal & 9,5 & 6,74 \\
\hline & PIB por habitante real ${ }^{(\mathrm{a})}$ & 4 & 3,36 \\
\hline \multicolumn{2}{|c|}{$(\mathrm{PIB} / \mathrm{VAB})(1)$} & 0,1 & 0,01 \\
\hline \multirow{2}{*}{$\begin{array}{l}\text { Productividad aparente del trabajo }=(\mathrm{VAB} / \\
\text { empleo })(2)\end{array}$} & Productividad aparente del empleo nominal & 8,5 & 5,05 \\
\hline & Productividad aparente del empleo real ${ }^{(\mathrm{a})}$ & 3,05 & 1,67 \\
\hline \multicolumn{2}{|c|}{ (VAB/VAB cooperativo) (3) } & $-9,8$ & 18,23 \\
\hline \multirow{2}{*}{$\begin{array}{l}\text { Productividad aparente del trabajo de las } \\
\text { cooperativas } \\
\text { (VAB cooperativo/empleo cooperativo) } \\
\text { (4) }\end{array}$} & Nominal & 10,7 & 14,89 \\
\hline & $\operatorname{Real}^{(\mathrm{a})}$ & 5,2 & 11,51 \\
\hline \multicolumn{2}{|c|}{$\begin{array}{l}\text { Generación de empleo cooperativo sobre el empleo total } \\
\qquad(\text { empleo cooperativo/empleo) }(5)\end{array}$} & 7,6 & $-22,66$ \\
\hline \multicolumn{2}{|c|}{ Generación de empleo sobre la población (empleo/población) (6) } & 0,85 & 1,59 \\
\hline
\end{tabular}

Nota. (a) Crecimiento real $=$ Crecimiento nominal-inflación. Inflación promedio en TCMAA $=5,5$ y 3,38 \% entre 2003-2010 y 20102015 , respectivamente.

Fuente. Alarcón, 2013, y Cuentas Nacionales del DANE.

Así las cosas, en el periodo 2003-2010, el crecimiento del PIB per cápita real ${ }^{9}$ fue superior al del periodo posterior, pasando del 4 al 3,36\% anual medio acumulativo (Tabla 3). Un detonante de lo anterior fue la depreciación del peso colombiano frente al dólar, a la vez que los precios petroleros descendieron en similar proporción (Toro, Garavito y López, 2016).

\footnotetext{
${ }^{9}$ En adelante se analizarán los agregados económicos descontada la inflación.
} 
Respecto a la productividad aparente del trabajo PIB/empleo-, su crecimiento a nivel nacional se desacelera desde el 3,05 por 100 anual acumulativo al 1,67 por 100 para los periodos 2003-2010 y 2010-2015, respectivamente. En las cooperativas, el crecimiento de la productividad aparente del trabajo se duplica entre los periodos considerados, desde el $5,2 \%$ de crecimiento anual al $11,51 \%$.

Esta cifra da cuenta del incremento del diferencial de crecimiento de la productividad del trabajo en las cooperativas respecto al crecimiento medio nacional, si bien el cooperativismo colombiano es la mitad de productivo que la media nacional en el 2003, y pasa alcanzar el $60 \%$ en el 2010 y el $75 \%$ en el 2015 -PAT media nacional $=100-$. Lo anterior se explica por el efecto de la liquidación de CTA.

Las cifras señalan una pérdida de casi 350000 empleos entre el 2011 y el 2016 —unos 90000 asalariados - (Tabla 3). Dado que muchas de ellas servían de figura para la intermediación de trabajos en fuentes intensivas en uso de mano de obra, se trataba de puestos de trabajo en precario que pasan a eliminarse del empleo cooperativo, de manera que, aunque el VAB cooperativo se reduzca, el empleo cooperativo se redujo más que proporcionalmente, con el consecuente incremento de la productividad por empleado. Aunque bien es cierto que ese empleo se fue absorbiendo por el resto de la economía, aunque dejara de pertenecer al cooperativismo.

De esa manera, una parte de las CTA que servían de intermediarias del mercado laboral en actividades intensivas en mano de obra hacen descontar el denominador de la productividad de organizaciones cooperativas. En el sector financiero, sector de mayor rentabilidad por empleado, cuando se pierde empleo se termina por ganar, aparentemente, en productividad general. Sin embargo, ofrecer afirmaciones acerca del resultado neto de la productividad requeriría contar con datos más precisos, como, por ejemplo, productividad por hora empleada, una medida que evitaría el sesgo de la temporalidad y la parcialidad del empleo.
En relación con la generación de empleo cooperativo sobre el empleo total -empleo cooperativo/ empleo- decrece desde una tasa de variación relativa del 7,6 \%, entre el 2003 y el 2010 , a una caída del $22,6 \%$ en el segundo periodo. Las cifras explican la incidencia de la drástica reducción de CTA en el país, con crecimiento del empleo total y caída del cooperativo. Pero también depura un error frecuente en el registro de la información estadística de las CTA cuando en la información proporcionada no se distinguía entre asociados y trabajadores, lo que duplicaba la información en muchos casos (véase la Tabla 3).

En cuanto al crecimiento del empleo con relación a la población, pasa de una tasa de crecimiento media anual acumulativa en el periodo 2003-2010 de 0,85\% a 1,59\%, esta en el periodo de 2010-2015. Lo anterior muestra, fundamentalmente, que el crecimiento de la población ha sido menor al crecimiento del empleo, a pesar de que en el conjunto del periodo de estudio esta generación de empleo se desacelera, lo cual implica, también, cierta desaceleración - no estancamiento ni decrecimiento - de la población (véase la Tabla 3).

Como apunte final, es menester mencionar que a la liquidación de las CTA se suma el decrecimiento financiero del sistema cooperativo luego de la intervención, durante el 2015, de Saludcoop, la mayor cooperativa en términos financieros del país, $y$ de la presión a la salida, a partir del 2010, del mayor subsector de generación de empleo, como lo es el de las cooperativas de trabajo asociado.

Mientras tanto, los sectores productivos cooperativos que mantienen el empleo vienen a coincidir con los que más apego al territorio tienen, de modo que constituyen esos hábitos y rutinas cooperativas con cierta preferencia en segmentos rurales de la población ocupados por grupos de respuesta que, en periodo de paz, tienden a ser la base sobre la que incorporan parte del sector servicios, en aspectos de cuidado del entorno ambiental y el turismo rural, la educación cooperativa- y las comunicaciones y el transporte, así como la agricultura y su transformación, es decir, la agroindustria. 


\section{Conclusiones}

$\mathrm{E}^{2}$ n Colombia se suele señalar, por parte de los gremios cooperativos y sus organismos de promoción y control, el potencial del cooperativismo como medio de desarrollo sostenible, la mejora de los servicios a los miembros y el interés general que producen acciones concretas de redistribución de ingresos — bien sea endógenas, a través de las TSE o bien exógenas- $-y$ de inclusión socioeconómica de colectivos no atendidos por el mercado o por el Estado - generando una liberación de recursos para sus beneficiarios, una rutina cooperativa y, por ende, para la sociedad-.

Pero si no hay indicadores para su contraste y para su estudio, los ejemplos puntuales y las buenas prácticas de algunas de las organizaciones que buscan su sostenibilidad integral y la de la economía a la que pertenecen no servirán a un efecto contagio para potenciar un segmento cooperativo caracterizado por un menor nivel de capitalización física y, por tanto, de productividad general.

Conscientes de que la aportación diferencial de la economía social y, por ende, de la economía cooperativa, que viene de la mano de las distintas manifestaciones de valor social más que desde el valor económico material-monetario, no puede obviarse la indudable contribución de este componente. En efecto, ante una falta de indicadores - necesaria para un cálculo extenso de las TSE ampliadas - se presenta aquí un intento de cálculo para las cooperativas colombianas sobre los diferenciales salariales.

De esta manera, las cifras presentadas respaldan su aporte material y social, y que sus principales subsectores de participación en el sistema económico apoyan, numéricamente, las relaciones con el mercado y con el Estado. Por tanto, la estrategia cooperativa convive con la competitiva de las sociedades capitalistas y con la redistributiva de la economía pública.
La medición presentada potencia la evaluación del impacto de la incidencia de las políticas públicas dirigidas al cuidado y fomento del cooperativismo. Su evaluación requiere de una variable nuclear asociada a la propuesta teórica, y en parte aplicada, que subyace en este trabajo: la emisión de TSE ampliadas.

En el periodo estudiado, las políticas públicas aplicadas develan la concurrencia de dispersos mecanismos entre la promoción y la supervisión que terminaron con la liquidación de miles de cooperativas de trabajo asociado y la desestructuración de otras entidades —como Saludcoop- que terminaron rezagando el crecimiento sostenido que presentaban las cooperativas.

En concreto, el cooperativismo alcanzó un peso relativo notable en la economía colombiana entre el 2003 y el 2010, pero su influencia disminuyó en el periodo 2010-2016, fruto, en parte, de la liquidación de miles de CTA, las cuales no transitaron un proceso de optimización empresarial previo. El valor añadido bruto de las cooperativas sobre el total nacional pasa del 0,83 \% en el 2003 al 0,56 \% en el 2016. Con todo, las TSE sobre el total nacional solo decrecen del 0,96\% en el 2010 al 0,87 \% en el 2016, en menor medida de lo que lo hizo el VAB, lo que demuestra la orientación organizacional al beneficio común y al interés general: las TSE son inelásticas al ciclo económico.

Por otra parte, la contribución del cooperativismo colombiano al crecimiento económico, concretado en el PIB por habitante, se puede dividir en la aportación del crecimiento de la productividad del trabajo cooperativo al crecimiento de la productividad general del trabajo del país, y en el incremento de la generación de empleo cooperativo respecto a la población. Mientras el crecimiento dela productividad real colombiana casi se divide por dos, entre una etapa y otra, el crecimiento de la productividad real de las cooperativas es mayor al doble. 
Además, y concretamente centrados en la productividad cooperativa, entre el 2003 y el 2010 se divide, y entre el 2010 y el 2015 es mayor al doble, en buena medida por la pérdida de empleo de las CTA, al ser el número de ocupados el denominador de la productividad del trabajo.

No obstante, la desventaja en capital físico y productividad del cooperativismo respecto al sistema general hace que, al no seguir su lógica, se vea arrastrado por el crecimiento y decrecimiento general de la economía. Pero lo hace sin la lógica de la causación acumulativa: no es capitalista.

Desacelera más despacio o crece por el denominado «efecto alcance»: al iniciarse en niveles monetarios menores de acumulación que el sistema general, sus crecimientos son más intensivos al acumular sobre números menores. Es lo que ocurre con las diferencias de crecimiento material monetario entre países desarrollados y en desarrollo. Ahora bien, el proceso debe tener en cuenta que las CTA liquidadas dejan de pertenecer al cooperativismo y sus empleos pasan al sistema general capitalista, de manera que hay cierto efecto espejo en las pérdidas de productividad del trabajo del sistema general y ganancias en el segmento cooperativo.
En definitiva, las cifras materiales-monetarias dan cuenta de cómo el crecimiento cooperativo se vio mermado por políticas poco asertivas de optimización organizacional, lo cual demanda una mejora de la información, recrear incentivos para aumentar las transferencias de las cooperativas a los asociados y propiciar una diversificación de su presencia en el territorio, especialmente en los ámbitos de transformación y producción.

Se trata de caminos pendientes de recorrer en materia de políticas públicas si se aspira a generar actuaciones que acerquen los resultados al potencial de estas organizaciones en cuanto generadoras de una institucionalidad que acerca a los ciudadanos a la inclusión socioeconómica y a la satisfacción de derechos económicos, sociales, políticos, culturales y ambientales.

Con todo, el crecimiento cooperativo ha sido notable para el fortalecimiento de la economía en su conjunto, medido por el estándar material-monetario de vida. Esto, al ser conscientes de que, primero, lo ideal es complementarlo con la contribución de indicadores de desarrollo más integrales, alternativos a ese estándar, que incorporen el desarrollo social y ambiental, y segundo, que ese estándar mantiene una muy alta correlación con indicadores más integrales, como, por ejemplo, el IDH o los desempeños en el cumplimiento de los ODS a través de la Agenda 2030. 


\section{Referencias}

Alarcón, M. Á. (2011). Incidencia de la economía social y solidaria en las cuentas nacionales. Hacia una identificación de su necesidad y un mapeo de la experiencia europea. En J. F. Álvarez (Comp.) Innovación y Economía Social y solidaria. (3972). Barranquilla: Ibarra Garrido. Recuperado de https://bit. ly/3csvbgt

Alarcón, M. Á. (2013). Las cuentas del cooperativismo de Colombia. Magnitudes cuantitativas e impacto económico 2003-2010. Bogotá: Cenicoop.

Alarcón, M. Á. (2016). La economía social desde el institucionalismo económico. Evidencia empírica. CIRIECEspaña, Revista de Economía Pública, Social y Cooperativa, (86), 61-100. Recuperado de https://bit.ly/2Bi0VYU

Alarcón, M. Á.; Álvarez, J. F. (2018). La dimensión sectorial del cooperativismo colombiano a través de un análisis de redes. CIRIEC-España, Revista de Economía Pública, Social y Cooperativa, (92), 121-154. DOI: https://doi.org/10.7203/ CIRIEC-E.92.10606

Álvarez, J. F. (2016). Articulación de políticas públicas dirigidas a las cooperativas. Propuestas para el caso colombiano en el marco de la convivencia pacífica y la internacionalización. Lisboa: Universidad de Lisboa.

Álvarez, J. F. (2017). Economía social y solidaria en el territorio: significantes y co-construcción de políticas públicas. Bogotá: Escuela Javeriana de Gobierno y Ética Pública.

Álvarez, J. F.; Alarcón, M. Á. (2019). Relaciones entre los ODS, el Plan para una Década Cooperativa y el balance social en cooperativas. Documento presentado en la Conferencia Internacional de UNTFSSE, Ginebra, 25-26 de junio. Recuperado de https://bit.ly/2XlL5Fl

Álvarez, J. F.; García-Müller, A. (2013). Las cooperativas de trabajo asociado y su instrumentalización en Colombia. Revista Idelcoop, 211, 28-44. Recuperado de https://bit. ly/3cpaBgY

Barea, J.; Monzón, J. (2006). Manual para la elaboración de las cuentas satélite de las empresas de la economía social: cooperativas y mutuas. Valencia: CIRIEC España.

Bassi, A.; Vincenti, G. (2015). Toward a new metrics for the evaluation of the social added value of social enterprises. Revista de Economía Pública, Social y Cooperativa, 83, 9-42. Recuperado de https://bit.ly/2ZW6RRA

Bedoya, R.; Caruso, N. (2006). Hacia un balance de las cooperativas de trabajo asociado. Ensayos laborales no. 15. Medellín: Escuela Nacional Sindical.

Bernal, A. (2008). Modelo alternativo de desarrollo para una economía nacional, plural, democrática y participativa. Bogotá: Editorial Oveja Negra.
Bouchard, M.; Rousselière, D. (2015). The weight of the social economy. An international perspective. Bruselas: Peter Lang.

Brundtland, G. H. (1987). Nuestro futuro común. Nueva York: Naciones Unidas.

Cenicoop. (2015). Lecciones aprendidas en el marco de la investigación. Impacto Social y Económico del Cooperativismo en Colombia. Bogotá: Cenicoop.

CES-España (Consejo Económico y Social-España). (2016). Informe Nuevos hábitos de consumo, cambios sociales $y$ tecnológicos. Colección Informes, Número 04/2016. Madrid: Consejo Económico y Social. Recuperado de https://bit. ly/3dnYulX

Chaves, R.; Monzón, J. L. (2017). Evolución reciente de la economía social en la Unión Europea. Bruselas: Comité Económico y Social Europeo.

DANE. (2005). Caracterización de las instituciones sin fines de lucro en Colombia. Dirección de Síntesis y Cuentas Nacionales. Bogotá: DANE.

Díaz, M.; Marcuello, C. (2010). Impacto económico de las cooperativas. La generación de empleo de las sociedades cooperativas y su relación con el PIB. CIRIEC-España. Revista de Economía Pública, Social y Cooperativa, 67, 23-44. Recuperado de https://bit.ly/2AqKIjU

Etxezarreta, E.; Mendiguren, J.; Díaz, L.; Errasti, A. (2018). Valor social de las cooperativas sociales: aplicación del modelo poliédrico en la cooperativa para la acogida de menores Zabalduz S. Coop. Revista de Economía Pública, Social y Cooperativa, (93), 155-180. DOI: https://doi.org/10.7203/ CIRIEC-E.93.9953

Farné, S. (2008). Las cooperativas de trabajo asociado en Colombia: balance de la política gubernamental, 20022007. Revista de Economía Institucional, 10(18), 261-285. Recuperado de https://bit.ly/2zQsecx

Felber, C. (2012). La economía del bien común. Barcelona: Deusto.

Franco, W.; Sarmiento, D.; Serrano, G.; Suárez, G. (2015). Orientación técnica sobre entidades sin ánimo de lucro. Documento de orientación técnica 14. Bogotá: Consejo Técnico de la Contaduría Pública. Recuperado de https://bit.ly/2XoeIG8

INE-Ciriec. (2014). Cuentas satélite de las cooperativas y mutuas en España (CSCME). Madrid: INE. Recuperado de https://bit. ly/2XRNaYI

OIT-ACI. (2014). Las cooperativas y los Objetivos de Desarrollo Sostenible. Debate sobre el desarrollo después de 2015. Informe de política. Ginebra

ONU. (1993). Sistema de Cuentas Nacionales 1993. Nueva York: ONU. 
ONU. (2008). Sistema de Cuentas Nacionales 2008. Nueva York: ONU.

ONU (2018). Informe de los Objetivos de Desarrollo Sostenible 2018. Nueva York: ONU

Retolaza, J.; San-José, L.; Ruíz-Roqueñi, M. (2015). Monetarizing the social value: theory and evidence. CIRIEC-Espana. Revista de Economía Pública, Social y Cooperativa, (83), 43-62. Recuperado de https://bit.ly/36PPmE4

Rodríguez, N. (1993). Sistema de información que permita obtener la matriz de insumo-producto en las organizaciones cooperativas (Tesis de maestría) Universidad Central, Colombia.

Rodríguez, N.; Sánchez, C.; Álvarez, J. F.; Fajardo, M. (2016). Medición del impacto socioeconómico del cooperativismo: propuesta para su cálculo. Bogotá: Instituto de Estudios del Ministerio Público.

Salathé-Beaulieu, G.; Bouchard, M. Y; Mendell, M. (Octubre de 2019). Sustainable development impact indicators for social and solidarity economy. State of the art. Working Paper 20194 UNRISD. Ginebra: United Nations Research Institute for Social Development. Recuperado de https://bit.ly/36S9zsW

Toro, J.; Garavito, A.; López, D. M. (2016). El choque petrolero $y$ sus implicaciones en la economía colombiana. Borradores de economía 906. Bogotá: Subgerencia de Estudios Económicos del Banco de la República.

Ward, B. (1958). The firm in Illyria: market syndicalism. American Economic Review, 48(4), 566-589. 